\title{
Aproveitamento de soro de queijo para produção de iogurte probiótico
}

\author{
[The use of cheese whey for probiotic yogurt production] \\ D.S. Soares ${ }^{1}$, A.E.C. Fai ${ }^{2}$, A.M. Oliveira ${ }^{3}$, E.M.F. Pires ${ }^{3}$, T.L.M. Stamford ${ }^{1}{ }^{*}$ \\ ${ }^{1}$ Departamento de Nutrição, Universidade Federal de Pernambuco, Recife/PE \\ ${ }^{2}$ Aluna de pós-graduação - Faculdade de Engenharia de Alimentos \\ Universidade Estadual de Campinas, Campinas, SP \\ ${ }^{3}$ Departamento de Tecnologia Rural, Universidade Federal Rural de Pernambuco - Recife, PE
}

\section{RESUMO}

Desenvolveu-se um iogurte natural aproveitando o soro de queijo de coalho, avaliando diferentes processos de pasteurização e concentração de leite em pó. Os iogurtes submetidos a $90^{\circ} \mathrm{C} / 5 \mathrm{~min}$ nas concentrações de $8 \%$ e $10 \%$ de leite em pó não apresentaram diferenças entre si $(\mathrm{P}>0,05)$ quanto à aceitação sensorial. Os produtos foram caracterizados como integral, atenderam às exigências de proteínas e forneceram mais de $15 \%$ do requisito diário recomendado de cálcio para crianças de um a 10 anos, satisfazendo as exigências de cálcio. Em ambas as formulações, o $\mathrm{pH}$ decresceu de aproximadamente 4,6 para 4,2 e a acidez aumentou de $0,7 \mathrm{~g}$ a $1,0 \mathrm{~g}$ de ácido láctico/100g do produto durante 28 dias de armazenamento. Não houve contaminação por Staphilococcus aureus, coliformes

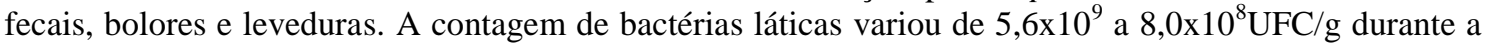
vida de prateleira, sugerindo a promoção de efeitos benéficos por este alimento probiótico. Concluiu-se que a utilização do soro para a produção de iogurte é uma alternativa viável ao agregar valor econômico, nutricional e funcional ao subproduto.

Palavras-chave: soro de leite, iogurte, vida de prateleira, impacto ambiental

\begin{abstract}
The objective of this work was to develop a natural yogurt utilizing the resultant whey of a "coalho" cheese production, assaying different processes of pasteurization and powdered milk concentrations. The yogurt submitted to $90^{\circ} \mathrm{C} / 5 \mathrm{~min}$ with 8 and $10 \%$ of powdered milk achieved the highest grade on sensorial analysis, with no significant difference $(P>0,05)$. Products were characterized as integral, attended the request for protein, and supplied over 15\% of the daily feed intake of calcium for children aged 1 to 10 , characterizing it as calcium enriched. In both formulations, the $p H$ decreased from 4.6 to 4.2 approximately and the acidity increased from $0.7 \mathrm{~g}$ to $1.0 \mathrm{~g}$ lactic acid/100g of product during 28 days of storage. There was no contamination by S. aureus, fecal coliforms, molds and yeasts. The counting of lactic bacteria varied from $5.6 \times 10^{9}$ to $8.0 \times 10^{8} \mathrm{CFU} / \mathrm{g}$ during shelf life, suggesting the promotion benefits from this probiotic product. It was concluded that whey utilization for yogurt production is a viable alternative to increase economic, nutritional, and functional value.
\end{abstract}

Keywords: milk whey, yogurt, shelf-life, environmental impact

\section{INTRODUÇÃO}

A formação de hábito alimentar é uma ação complexa que sofre interferência de diversas variáveis, por isso contínuos estudos visam agregar benefícios aos produtos que fazem

Recebido em 10 de janeiro de 2011

Aceito em 10 de junho de 2011

*Autor para correspondência (corresponding author)

E-mail: tlmstamford@yahoo.com.br parte da rotina alimentar do consumidor. $\mathrm{O}$ desenvolvimento de novos produtos também é considerado de grande importância, visto que a relação dieta-saúde representa um desafio para a ciência e a tecnologia de alimentos, principalmente quando se trata de alimentos funcionais. 
Segundo Komatsu et al. (2008) e Lima et al. (2009), alimentos funcionais são os que garantem efeito nutricional adequado e podem demonstrar benefícios adicionais em uma ou mais funções do organismo, proporcionado melhoras do estado de saúde e bem estar ou redução do risco de doenças. Viegas et al. (2010) afirmaram que o alimento funcional contendo microrganismos probióticos pode ser favorável à prevenção de infecções intestinais e diarreias, ter efeito anticarcinogênico, auxiliar na redução dos níveis de colesterol e melhorar a digestão da lactose.

Muitos alimentos têm mostrado avanços mercadológicos expressivos, incluindo as inovações de produtos lácteos, que ocorrem a uma taxa mais alta que à de qualquer outra classe de alimento (Nielsen, 2009). O iogurte é um deles. Está em plena expansão, pois somente no Brasil o consumo superou a marca de 465 milhões de quilos em 2007, quando foram movimentados, aproximadamente, 2 bilhões de dólares (Alysson, 2008). Assim, observa-se que os produtos lácteos conferem impacto positivo no mercado de alimentos, com boa perspectiva de crescimento. Mais ainda, pode-se considerar que a utilização de soro de queijo na elaboração de produtos lácteos fermentados constitui uma forma racional de aproveitamento desse resíduo, que apresenta excelente valor nutritivo (Almeida et al., 2001) e também proporciona meios de minimizar o problema ambiental causado pelo descarte (Ghaly e Kamal, 2004).

Desse modo, esta pesquisa teve como objetivo estudar diferentes relações da mistura leite-soro de queijo de coalho, para produção de iogurte natural, avaliando as características físicoquímicas, microbiológicas, sensoriais e a viabilidade celular das formulações preparadas.

\section{MATERIAL E MÉTODOS}

No soro de leite e no produto final, foram realizadas análises para determinação de umidade, extrato seco total, cinzas e cálcio seguindo a AOAC (Official..., 2002), teor de gordura pelo método de Gerber, proteínas pelo método de Kjeldahl e o teor de carboidratos calculado pela diferença entre os sólidos totais e o somatório dos teores de gordura, proteínas e cinzas. Todas as análises foram realizadas em triplicata.
Análises microbiológicas do soro visaram identificar o tratamento térmico mais eficiente. Para isso, utilizou-se como padrão o soro in natura, observando-se a eficiência da pasteurização a $65^{\circ} \mathrm{C} / 30 \mathrm{~min}$ (tratamento 1) e $90^{\circ} \mathrm{C} / 5 \mathrm{~min}$ (tratamento 2). Análises de coliformes totais e Escherichia coli, de bolores e leveduras, de Staphylococcus aureus e contagem padrão de bactérias aeróbias seguiram as normas da AOAC (Official..., 2002).

No preparo do iogurte, o substrato para fermentação foi constituído por soro de queijo de coalho, acrescido de leite em pó integral nas concentrações de $6 \%, 8 \%, 10 \%$ e $12 \%(\mathrm{~m} / \mathrm{v})$, previamente submetidos ao processo de pasteurização mais eficiente $\left(90^{\circ} \mathrm{C} / 5 \mathrm{~min}\right)$. Em seguida, ajustou-se a temperatura do substrato para $42 \pm 1^{\circ} \mathrm{C}$, seguido de inoculação com $10 \%$ da cultura-mãe previamente preparada contendo cepas de Lactobacillus bulgaricus e Streptococcus thermophilus (Diagramma SA) na proporção de 1:1, que foi incubado até atingir $\mathrm{pH}$ 4,5 $\pm 0,1$ e índice de acidez entre $0,6 \mathrm{~g}$ e $1,5 \mathrm{~g}$ de ácido láctico $/ 100 \mathrm{~g}$ e refrigerado a $4^{\circ} \mathrm{C}$.

Durante o desenvolvimento dos iogurtes, excluiuram-se a formulação com $6 \%$ de leite pela baixa viscosidade e a formulação com $12 \%$ pelo fato de apresentar viscosidade semelhante à do iogurte com $10 \%$ de leite, minimizando, assim, o custo da produção. Desse modo, todas as análises foram realizadas apenas nos iogurtes preparados com $8 \%$ e $10 \%$ de leite submetidos ao tratamento 2.

Para avaliação da vida de prateleira, os iogurtes foram analisados no dia de produção e após sete, 14,21 e 28 dias de armazenamento $\left(4^{\circ} \mathrm{C}\right)$ quanto ao pH e à acidez titulável (Official..., 2002). Paralelamente, foi realizada contagem de células viáveis de L. bulgaricus e S. thermophilus, segundo APHA (Compendium..., 2001). No dia de produção e no $28^{\circ}$ dia de armazenamento, também foram realizadas análises de coliformes totais e $E$. coli, de bolores e leveduras e de $S$. aureus e contagem padrão de bactérias aeróbias (Official..., 2002).

Os iogurtes produzidos com soro pasteurizado a $90^{\circ} \mathrm{C} / 5 \mathrm{~min}$ acrescido de $8 \%$ e $10 \%$ de leite em pó e adicionados de $10 \%$ de açúcar foram submetidos ao teste de aceitação sensorial - cor, sabor, odor e viscosidade - por 34 julgadores 
não treinados, sendo oferecidos a $4^{\circ} \mathrm{C}$. As análises, realizadas em cabines individuais com iluminação branca, em alíquotas de $25 \mathrm{~mL}$, foram servidas em copos descartáveis codificados. Água mineral foi servida para eliminação do sabor residual entre as amostras, que foram oferecidas separadamente. Os julgadores foram orientados para utilizar a escala hedônica de 9 pontos, 1 = desgostei muitíssimo; 9= gostei muitíssimo, para avaliação da aceitabilidade geral (Dutcosky, 1996).

Utilizou-se análise de variância seguida do teste de Duncan para comparação de médias e teste $t$ a 5\% de significância, fazendo-se uso do software Statistica 6.0 (Statsoft, 1997).

\section{RESULTADOS}

A avaliação microbiológica do soro demonstrou que houve diferença $(\mathrm{P}<0,05)$ quando se comparou a qualidade microbiológica do soro in natura com o soro submetido aos diferentes processos de pasteurização, evidenciando a necessidade e a eficácia dos tratamentos térmicos. A pasteurização realizada a $90^{\circ} \mathrm{C}$ durante cinco minutos foi mais efetiva que a $65^{\circ} \mathrm{C}$ por 30 minutos para a redução da contagem padrão de bactérias aeróbias, $S$. aureus, coliformes totais, E. coli, bolores e leveduras (Tab. 1), sendo, portanto, o tratamento térmico escolhido para tratamento do soro de leite antes da fermentação para produção do iogurte.

Tabela 1. Contagem microbiana (UFC/g) do soro de queijo de coalho in natura e submetido a diferentes temperaturas de pasteurização

\begin{tabular}{cccccccc} 
Amostra & Análise & $\begin{array}{c}\text { Contagem } \\
\text { padrão }\end{array}$ & S. aureus & $\begin{array}{c}\text { Coliformes } \\
\text { totais }\end{array}$ & E. coli & Bolores & Leveduras \\
\hline S & 1 & $>2,5 \times 10^{3}$ & $<1$ & $2,1 \times 10^{3}$ & $8,0 \times 10^{2}$ & $<1$ & $1,2 \times 10$ \\
S & 2 & $3,22 \times 10^{4}$ & $4,4 \times 10$ & $1,05 \times 10^{4}$ & $4,0 \times 10^{2}$ & $<1$ & $1,7 \times 10$ \\
S & 3 & $>2,5 \times 10^{4}$ & $2,9 \times 10$ & $1,82 \times 10^{4}$ & $1,0 \times 10^{2}$ & $<1$ & $2,8 \times 10^{2}$ \\
SP1 & 1 & $2,0 \times 10^{2}$ & $<1$ & $<1$ & $<1$ & $<1$ & $<1$ \\
SP1 & 2 & $6,8 \times 10^{2}$ & $<1$ & $<1$ & $<1$ & $<1$ & $<1$ \\
SP1 & 3 & $1,35 \times 10^{2}$ & $<1$ & $<1$ & $<1$ & $<1$ & $<1$ \\
SP2 & 1 & $<1$ & $<1$ & $<1$ & $<1$ & $<1$ & $<1$ \\
SP2 & 2 & 1 & $<1$ & $<1$ & $<1$ & $<1$ & $<1$ \\
SP2 & 3 & 6 & $<1$ & $<1$ & $<1$ & $<1$ & $<1$ \\
\hline
\end{tabular}

S: soro in natura; SP1: soro pasteurizado a $65^{\circ} \mathrm{C} / 30 \mathrm{~min}$; $\mathrm{SP} 2$ : soro pasteurizado a $90^{\circ} \mathrm{C} / 5 \mathrm{~min}$.

Após a caracterização microbiológica e da composição do soro de queijo de coalho (Tab. 2), iniciou-se o processo fermentativo para produção do iogurte, o qual teve duração de quatro horas e 30 minutos de incubação a $42^{\circ} \mathrm{C} \pm 1^{\circ} \mathrm{C}$. Os iogurtes com $8 \%$ e $10 \%$ de leite foram refrigerados a $4^{\circ} \mathrm{C}$ para avaliação da vida de prateleira, observando-se as modificações dos índices de $\mathrm{pH}$ e acidez acompanhados no dia de produção e durante o período de sete, 14, 21 e 28 dias de estocagem (Fig. 1). Em relação ao pH, em ambas as formulações ocorreu decréscimo de aproximadamente 4,6 para 4,2 e aumento da acidez de $0,70 \mathrm{~g}$ para $0,86 \mathrm{~g}$ de ácido láctico $/ 100 \mathrm{~g}$ no produto com $8 \%$ de leite e de $0,78 \mathrm{~g}$ para $0,98 \mathrm{~g}$ de ácido láctico/100g do iogurte com $10 \%$ de leite (Fig. 1).

Análises microbiológicas realizadas durante a avaliação da vida de prateleira dos iogurtes mostraram ausência de bactérias do grupo coliformes, S. aureus, fungos e leveduras. A contagem de bactérias láticas de iogurtes com $8 \%$ e $10 \%$ de leite em pó no primeiro dia foi, para ambas as formulações, de $5,6 \times 10^{9} \mathrm{UFC} / \mathrm{g}$. No $28^{\circ}$ dia de armazenamento, as contagens de bactérias lácteas foram de $8,0 \times 10^{8}$ e $1,0 \times 10^{9} \mathrm{UFC} / \mathrm{g}$ nos iogurtes com $8 \%$ e $10 \%$ de leite em pó, respectivamente.

Tabela 2. Composição físico-química do soro de queijo de coalho in natura $(100 \mathrm{~g})$

\begin{tabular}{lc}
\hline $\begin{array}{c}\text { Determinação físico- } \\
\text { química }\end{array}$ & $\mathrm{X} \pm \mathrm{DP}$ \\
\hline Umidade $(\mathrm{g})$ & $93,05 \pm 0,64$ \\
Extrato seco $(\mathrm{g})$ & $6,95 \pm 0,64$ \\
Proteínas $(\mathrm{g})$ & $0,88 \pm 0,06$ \\
Lipídios $(\mathrm{g})$ & $0,42 \pm 0,05$ \\
Carboidratos $(\mathrm{g})$ & $5,64 \pm 0,63$ \\
Cinzas $(\mathrm{g})$ & $0,48 \pm 0,02$ \\
Cálcio $(\mathrm{mg})$ & $48,83 \pm 11,25$ \\
\hline
\end{tabular}




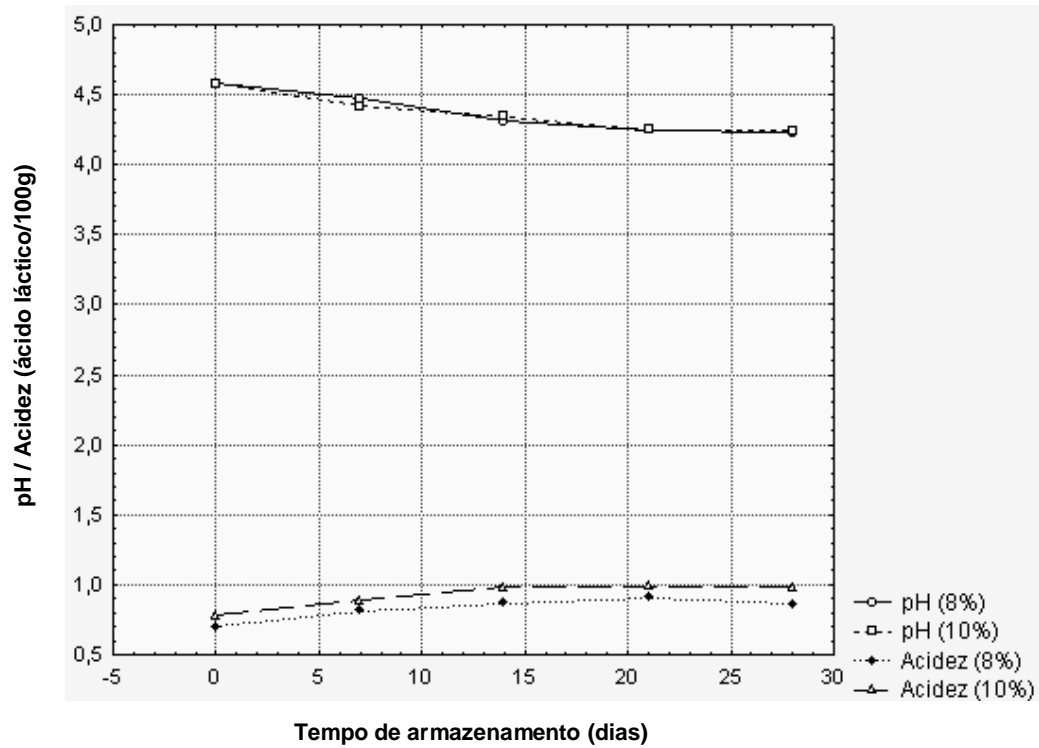

Figura 1. Variação do pH e acidez de iogurtes preparados com $8 \%$ e $10 \%$ de leite em pó durante o período de armazenamento.

A composição físico-química evidenciou que os teores de gordura, proteína, umidade, matéria seca e cinzas foram diferentes $(\mathrm{P}<0,05)$ em decorrência das diferentes proporções de leite utilizadas. Quanto aos carboidratos e aos teores de cálcio, não se constatou diferença $(\mathrm{P}>0,05)$ entre os leites utilizados (Tab. 3).
Os resultados da análise sensorial mostraram que não houve diferença $(\mathrm{P}>0,05)$ em relação aos atributos estudados quanto ao percentual de leite em pó utilizado na formulação dos iogurtes; ou seja, mesmo existindo alteração na concentração de leite em pó utilizado, os julgadores não perceberam, sensorialmente, essa diferença (Tab. 4).

Tabela 3. Composição físico-química de iogurtes produzidos com soro de queijo de coalho pasteurizado a $90^{\circ} \mathrm{C} / 5 \mathrm{~min}$ com diferentes concentrações de leite em pó

\begin{tabular}{lcc}
\hline Determinação físico-química & $\begin{array}{c}8 \% \text { de leite em pó } \\
(\mathrm{X} \pm \mathrm{DP})^{*}\end{array}$ & $\begin{array}{c}10 \% \text { de leite em pó } \\
(\mathrm{X} \pm \mathrm{DP})^{*}\end{array}$ \\
\hline Umidade $(\mathrm{g})$ & $85,47 \pm 0,61 \mathrm{a}$ & $83,60 \pm 0,98 \mathrm{~b}$ \\
Extrato seco $(\mathrm{g})$ & $14,52 \pm 0,61 \mathrm{~b}$ & $16,39 \pm 0,98 \mathrm{a}$ \\
Proteínas $(\mathrm{g})$ & $2,89 \pm 0,16 \mathrm{~b}$ & $3,32 \pm 0,38 \mathrm{a}$ \\
Lipídeos $(\mathrm{g})$ & $3,02 \pm 0,33 \mathrm{~b}$ & $3,67 \pm 0,23 \mathrm{a}$ \\
Carboidratos $(\mathrm{g})$ & $8,61 \pm 0,84 \mathrm{a}$ & $9,40 \pm 1,08 \mathrm{a}$ \\
Cinzas $(\mathrm{g})$ & $0,92 \pm 0,02 \mathrm{~b}$ & $0,99 \pm 0,01 \mathrm{a}$ \\
Cálcio $(\mathrm{mg})$ & $119,09 \pm 29,49 \mathrm{a}$ & $127,92 \pm 27,65 \mathrm{a}$ \\
\hline
\end{tabular}

*Letras diferentes na mesma linha indicam diferenças entre valores pelo teste de Duncan $(\mathrm{P}<0,05)$.

Tabela 4. Aceitação sensorial dos iogurtes produzidos com soro de queijo de coalho pasteurizado a $90^{\circ} \mathrm{C} / 5 \mathrm{~min}$ com diferentes concentrações de leite em pó

\begin{tabular}{lcc}
\hline \multicolumn{1}{c}{ Atributo sensorial } & $\begin{array}{c}8 \% \text { de leite em pó } \\
(\mathrm{X} \pm \mathrm{DP})^{*}\end{array}$ & $\begin{array}{c}10 \% \text { de leite em pó } \\
(\mathrm{X} \pm \mathrm{DP})^{*}\end{array}$ \\
\hline Cor & $7,20 \pm 1,55$ & $7,12 \pm 1,53$ \\
Sabor & $8,00 \pm 1,21$ & $7,85 \pm 1,02$ \\
Odor & $7,82 \pm 0,88$ & $7,41 \pm 0,96$ \\
Viscosidade & $7,26 \pm 1,88$ & $7,56 \pm 1,54$ \\
\hline
\end{tabular}

* Não houve diferença entre os tratamentos. 


\section{DISCUSSÃO}

A pasteurização aplicada ao soro de queijo de coalho mostrou sua eficiência pela capacidade de reduzir a população de mesófilos, S. aureus, coliformes totais e $E$. coli presentes no soro leite in natura. Evidencia-se, portanto, que o cumprimento dessa etapa minimiza a exposição do consumidor a sério risco de contaminação por uma variedade de microrganismos patogênicos presentes na matéria-prima (Fai et al., 2009). É válido destacar que a pasteurização também atua na eliminação dos microrganismos deteriorantes, os quais podem causar degradação de gorduras, proteínas e carboidratos, tornando-os impróprios para o consumo humano (Tamanini et al., 2007).

De acordo com o Regulamento Técnico de Identidade e Qualidade de Soro de Leite (Regulamento..., 2010), o soro utilizado neste trabalho foi caracterizado como doce, pois apresentou $\mathrm{pH}$ entre 6,0 e 6,8. Observou-se, ainda, que sua composição foi semelhante à comumente descrita na literatura, a qual demonstra a retenção de aproximadamente $55 \%$ dos nutrientes totais do leite, sendo os mais abundantes: lactose $45 \mathrm{~g} / \mathrm{L}$ a $50 \mathrm{~g} / \mathrm{L}$ - proteínas solúveis - 6g/L a $8 \mathrm{~g} / \mathrm{L}-$, lipídios $-4 \mathrm{~g} / \mathrm{L}$ a $5 \mathrm{~g} / \mathrm{L}$ -e sais minerais $-8 \%-10 \%$ de extrato seco incluindo $\mathrm{NaCl}$ e $\mathrm{KCl}$ (mais que $50 \%$ ), sais de cálcio, principalmente fosfato, e outros. Quantidades apreciáveis de ácido láctico $(0,5 \mathrm{~g} / \mathrm{L})$ e ácido cítrico, compostos nitrogenados não proteicos (ureia e ácido úrico) e vitaminas do complexo B são também encontradas no soro (Dragone et al., 2009).

Culturas de iogurte como L. bulgaricus e $S$. thermophilus mantêm-se ativas nas temperaturas de refrigeração e conseguem produzir pequenas quantidades de ácido láctico por fermentação da lactose, resultando em perceptível diminuição do pH. Mas algumas cepas probióticas mostram sensibilidade à acidez, e este problema é agravado pela pós-acidificação no armazenamento, promovido pela $\beta$-galactosidase que ainda permanece ativa de $0^{\circ} \mathrm{C}$ a $5^{\circ} \mathrm{C}$. Neste caso, pode haver comprometimento na contagem de células microbianas probióticas, além da separação do soro (Thamer e Penna, 2006).

Este aspecto pode ser observado na Fig. 1, onde a acidez média aumentou e o $\mathrm{pH}$ diminuiu nos dois tipos de iogurte durante a estocagem, mas cabe ressaltar que, ainda assim, encontram-se em conformidade com o padrão de identidade e qualidade de iogurtes (Brasil, 2000), que estabelece o limite de $0,6 \mathrm{~g}$ a $1,5 \mathrm{~g}$ de ácido láctico/100g de produto.

Os iogurtes desenvolvidos neste estudo mantiveram a inocuidade durante a avaliação da vida de prateleira, pois, no decorrer dos 28 dias de investigação, não foram detectados microrganismos que configurassem uma situação de contaminação. Vale destacar que a presença de microrganismos probióticos pode ter influenciado na manutenção da inocuidade dos iogurtes. Mazochi et al. (2010) afirmaram que estes agem por antagonismo direto contra espécies patogênicas pela produção de metabólitos - ácidos orgânicos, peróxido de hidrogênio, antibióticos e bacteriocinas -, por competição nutricional e sítios de adesão em mucosas por modulação do sistema imune do hospedeiro e por produção de enzimas que melhoram a digestão ou detoxificam os metabólitos da microbiota patogênica.

Durante a vida de prateleira, o alimento deve atender às exigências de qualidade determinadas pela legislação vigente, principalmente quanto à viabilidade de microrganismos probióticos (Coelho et al., 2009). A contagem destes no alimento deve chegar a $10^{9} \mathrm{UFC} / \mathrm{g}$ para que, aproximadamente, $10^{3} \mathrm{UFC} / \mathrm{g}$ a $10^{4} \mathrm{UFC} / \mathrm{g}$ alcancem os intestinos, sendo $10^{6} \mathrm{UFC} / \mathrm{g}$ a contagem ideal (Matsubara, 2001). A legislação brasileira estabelece um limite mínimo de $10^{7}$ UFC/g para as bactérias láticas totais no iogurte, determinando que esses microrganismos específicos sejam viáveis, ativos e abundantes no produto final e durante toda sua vida de prateleira (Brasil, 2000).

É importante ressaltar, porém, que a ciência discute quanto ao caráter probiótico in vivo dos microrganismos do iogurte, L. bulgaricus e $S$. thermophilus, uma vez que benefícios como a digestão da lactose, as respostas imunomoduladoras e os efeitos antihipertensivos estão relacionados, também, a estas cepas. Nestes casos, o efeito positivo à saúde estaria atrelado a células não viáveis ou componentes celulares, a atividades enzimáticas e a produtos fermentativos. Nessa área de estudos, existe uma contestação quanto à ideia de o termo probiótico incluir microrganismos não 
viáveis e até mesmo fragmentos celulares destes, emergindo, assim, o conceito de "substânciasativas probióticas" (Komatsu et al., 2008). Neste âmbito de concepção, o iogurte produzido neste estudo pode ser caracterizado como probiótico.

Em relação à composição físico-química, a legislação vigente (Brasil, 2000) determina que, quanto aos teores de lipídios, os produtos sejam considerados desnatados, parcialmente desnatados, integrais ou com creme, e variem de $0,5 \mathrm{~g} \%$ até $6,0 \mathrm{~g} \%$. Dessa forma, pode-se dizer que o valor médio obtido de $3,02 \pm 0,33 \mathrm{~g}$ e de $3,67 \pm 0,23 \mathrm{~g}$ nos iogurtes com $8 \%$ e $10 \%$ de leite, respectivamente, caracteriza-os como integral. Esta legislação determina, também, um mínimo de $2,9 \mathrm{~g} / 100 \mathrm{~g}$ de proteína em iogurtes, parâmetro também alcançado por ambas as formulações desenvolvidas.

Deve-se ressaltar que os produtos obtidos neste estudo podem ser considerados como fonte de cálcio (Brasil, 1998; Brasil, 2005), pois apresentaram $119,09 \pm 29,49 \mathrm{mg} / 100 \mathrm{~g} \quad$ e $127,92 \pm 27,65 \mathrm{mg} / 100 \mathrm{~g}$ para $8 \%$ e $10 \%$ de leite utilizado, respectivamente. Estes valores representam mais de $15 \%$ da ingestão diária recomendada para crianças nas faixas etárias de 1 a 10 anos - 500mg a 700mg de cálcio.

No estudo sensorial dos iogurtes, obteve-se ótima aceitação, e as diferenças entre as formulações não foram perceptíveis aos julgadores $(\mathrm{P}<0,05)$, considerando os atributos cor, sabor, odor e viscosidade. Estes dados permitem concluir que há viabilidade comercial para a produção desta bebida e que, economicamente, é mais viável a produção do iogurte com $8 \%$ de leite em pó integral.

O soro integral in natura apresenta baixa aceitação sensorial pelo alto teor de cinzas (Siqueira et al., 2002), mas considerando as características nutricionais e funcionais, desde a década de 60 , pesquisadores e indústrias buscam a diversificação de produtos elaborados a partir desse resíduo (Cruz et al., 2009). Dessa forma, o uso do soro do leite justifica-se não só por suas características nutricionais de excelência, mas também por configurar uma estratégia para reduzir o impacto ambiental que este resíduo agroindustrial representa ao meio ambiente.

\section{CONCLUSÕES}

Os iogurtes desenvolvidos atenderam aos parâmetros das legislações vigentes, caracterizando-se como integrais e como fontes de cálcio e probióticos. $\mathrm{O}$ processo de pasteurização foi eficiente e influenciou positivamente no controle de qualidade dos iogurtes durante a vida de prateleira, indicando a qualidade microbiológica dos produtos e do processo. A viabilidade da produção do iogurte com menor concentração de leite em pó mostrouse possível pela sua significativa aceitação sensorial, repercutindo positivamente na maior aplicabilidade do soro de queijo de coalho em produtos lácteos fermentados.

\section{REFERÊNCIAS BIBLIOGRÁFICAS}

ALMEIDA, K.E.; BONASSI, I.A.; ROÇA, R.O. Características físicas e químicas de bebidas lácteas fermentadas e preparadas com soro de queijo minas frescal. Cienc. Tecnol. Aliment., v.21, p.187-192, 2001.

ALYSSON, E. Na rota dos lácteos. Industr. Latic., n.75, p.38-41, 2008.

BRASIL. Ministério da Agricultura e do Abastecimento. Resolução $\mathrm{n}^{\circ}$ 5, de 13 de novembro de 2000. Padrões de identidade $e$ qualidade de leites fermentados. Diário Oficial da União, Brasília, 27 nov. 2000.

BRASIL. Ministério da Saúde. Portaria no 31, de 13 de janeiro de 1998. Regulamento técnico para fixação de identidade e qualidade de alimentos adicionados de nutrientes essenciais. Diário Oficial da União, Brasília, 16 jan. 1998.

BRASIL. Ministério da Saúde. Resolução RDC $\mathrm{n}^{\circ} 269$, de 22 de setembro de 2005, Regulamento técnico sobre ingestão diária recomendada (IDR) para proteína, vitaminas e minerais. Diário Oficial da União, Brasília, 23 set. 2005.

COELHO, F.J.O.; QUEVEDO, P.S. MENIN, A. et al. Avaliação do prazo de validade do iogurte. Cienc. Anim. Bras., v.10, p.1155-1160, 2009.

COMPENDIUM of methods for the microbiological examination of foods. 4.ed. Washington: APHA, 2001. 
CRUZ, A.G.; SANT'ANA, A.S.; MACCHIONE, M.M. et al. Milk drink using whey butter cheese (queijo manteiga) and acerola juice as a potencial souce of vitamin C. Food Bioprocess Technol., v.2, p.368-373, 2009.

DRAGONE, G.; MUSSATTO, S.I.; OLIVEIRA, J.M. et al. Characterization of volatile compounds in an alcoholic beverage produced by whey fermentation. Food Chem., v.112, p.929935, 2009.

DUTCOSKY, S.D. Análise sensorial de alimentos. Curitiba: Champagnat, 1996. 123p.

FAI, A.E.C.; OLIVEIRA, A.M.; SOARES, D.S. et al. Avaliação da qualidade de queijos de coalho comercializados no entorno da Cidade Universitária, Recife/PE. Hig. Alim., v.23, p.160165, 2009.

GHALY, A.E.; KAMAL, M.A. Submerged yeast fermentation of acid cheese whey for protein production and pollution potential reduction. Water Res., v.38, p.631-644, 2004.

KOMATSU, T.R.; BURITI, F.C.A.; SAAD, S.M.I. Inovação, persistência e criatividade superando barreiras no desenvolvimento de alimentos probióticos. Rev. Bras. Cienc. Farm., v.44, p.329-347, 2008.

LIMA, M.S.; REVILLION, J.P.P.; PADULA, A.D. Estratégias competitivas e de desenvolvimento de produtos lácteos funcionais: estudos de caso em empresas agroindustriais da região Sul do Brasil. Cienc. Rural, v.39, p.15471551, 2009.

MATSUBARA, S. Alimentos Funcionais: uma tendência que abre perspectivas aos laticínios. Industr. Latic., v.34, p.10-18, 2001.

MAZOCHI, V.; MATOS JÚNIOR, F.E.; VAL, C.H. et al. Iogurte probiótico produzido com leite de cabra suplementado com bifidobacterium spp. Arq. Bras. Med. Vet. Zootec., v.62, p.14841490, 2010.
NIELSEN. Os produtos mais quentes do mundo. Disponível em: <http://br.nielsen.com/reports/documents/Whats HotInsightsonGrowthinFoodBeverageProductsBr Pt.pdf>. Acessado em: 27 out. 2009.

OFFICIAL methods of analysis of the Association of Official Analytical Chemistry. 17.ed. Washington: AOAC, 2002. 1115p.

REGULAMENTO técnico de identidade e qualidade de soro de leite. Disponível em: http://www.terraviva.com.br/clique/minuta.html. Acessado em: 19 jan. 2010

SIQUEIRA, I.M.C.; SOUZA, M.R.; GLÓRIA, M.B.A. Importância e utilização dos derivados de soro de queijo. Hig. Alim., v.16, p.31-35, 2002.

STATSOFT. In: Statistica For Windows [computer program manual]. Tulsa, OK: Statsoft, Inc., 1997.

TAMANINI, R.; SILVA, L.C.C.; MONTEIRO, A.A. et al. Avaliação da qualidade microbiológica e dos parâmetros enzimáticos da pasteurização de leite tipo " $\mathrm{C}$ " produzido na região norte do Paraná. Semina Cienc. Agrar., v.28, p.449-454, 2007.

THAMER, K.G.; PENNA, A.L.B. Caracterização de bebidas lácteas funcionais fermentadas por probióticos e acrescidas de prebiótico. Cienc. Tecnol. Aliment., v.26, p.589595, 2006.

VIEGAS, R.P.; SOUZA, M.R.; FIGUEIREDO, T.C. et al. Qualidade de leites fermentados funcionais elaborados a partir de bactérias ácidolácticas isoladas de queijo de coalho. Arq. Bras. Med. Vet. Zootec., v.62, p.460-467, 2010. 